\section{P249 IT IS POSSIBLE TO DETECT ACTIVE NEUTROPHIL ELASTASE IN EXHALED BREATH CONDENSATE OF PATIENTS WITH CYSTIC FIBROSIS}

${ }^{1,2} \mathrm{C}$ Edmondson, ${ }^{1} \mathrm{R}$ Murphy, ${ }^{3} \mathrm{~K}$ Moffitt, ${ }^{3} \mathrm{D}$ Ribeiro, ${ }^{1,2,4} \mathrm{EWFW}$ Alton, ${ }^{1,2,4} \mathrm{JC}$ Davies. ${ }^{1} \mathrm{NHLI}$ Imperial College London, London, UK; ${ }^{2}$ Royal Brompton Hospital, London, UK; ${ }^{3}$ ProAxsis Ltd, Belfast, UK; ${ }^{4}$ UK CF Gene Therapy Consortium London, London, UK

\subsection{6/thoraxjnl-2017-210983.391}

Introduction $\mathrm{CF}$ is characterised by chronic progressive respiratory decline punctuated with periods of acute pulmonary exacerbations (PEx). Given the relationship between PEx number and chronic rate of decline and that $\sim 25 \%$ of PEx patients fail to regain their baseline $\mathrm{FEV}_{1}$, there remains a need for a reliable biomarker to predict PEx and/or monitor responses to treatment. Several biomarkers have been explored, including sputum Neutrophil Elastase (NE). However, any sputum-based biomarker will only be suitable for patients able to expectorate, whereas significant disease begins earlier in life. Previously, our group (Thorax 2013;68: 532-9) reported the change of physiological, functional and structural markers over a PEx within which we collected exhaled breath condensate (EBC). These samples were analysed with a newly-developed immunoassay; detection of NE would offer the potential to detect airway inflammation in non-expectorating subjects.

Methods EBC was collected using an Ecoscreen condenser, stored at $-80^{\circ} \mathrm{C}$, and then analysed using the ProteaseTag Active Neutrophil Elastase Immunoassay (ProAxsis Ltd).

Results 35 EBC samples from 19 participants were available. Participants were 12-44 years; 10 female. Median $\mathrm{FEV}_{1} \%$ predicted was 52.5\% (IQR 43.75\%-74.8\%). All had chronic Pseudomonas aeruginosa infection apart from 1 who had chronic Burkholderia cepacia complex infection. NE could be detected $(\geq \operatorname{LLD} 7.2 \mathrm{ng} / \mathrm{ml})$ in 28 of 35 samples $(80 \%)$. For the whole group, median concentration was $15.45 \mathrm{ng} / \mathrm{ml}$ (IQR $10.36-19.02 \mathrm{ng} / \mathrm{ml}$ ).

Discussion This was a small, pilot study seeking to demonstrate the feasibility of measuring active NE in EBC and successfully reporting, for the first time to our knowledge, detectable levels of this inflammatory marker. However, levels were near the lower end of detection of the immunoassay; therefore development of a more sensitive assay could be helpful. Further work is needed to establish CF/non-CF differences and the relevance of levels to accepted measures of airway disease. The use of EBC could allow monitoring of airway inflammation at the early stages of CF lung disease when patients cannot expectorate sputum, and during a period in their disease progression when the potential impact of interventions on long term outcomes may be greatest.

Supported by ProAxsis Ltd and the CF Trust UK

\section{P250 A NATIONAL STUDY OF NON-INVASIVE VENTILATION AND CLINICAL OUTCOMES IN CYSTIC FIBROSIS}

${ }^{1} \mathrm{O}$ Archangelidi, ${ }^{2} \mathrm{NJ}$ Simmonds, ${ }^{2} \mathrm{SB}$ Carr, ${ }^{1} \mathrm{P}$ Cullinan. ${ }^{1}$ Imperial College London, London, $\mathrm{UK}_{i}{ }^{2}$ Royal Brompton Hospital, London, UK

\subsection{6/thoraxjnl-2017-210983.392}

Introduction/Objectives Non-invasive ventilation (NIV) is often used as a 'bridge' to transplantation, for symptom control or as an adjunct to physiotherapy. Whether or not NIV is being appropriately used in UK patients with CF, successfully targeting those who will benefit most, is unknown; nor is there information on the life expectancy of those who start on NIV. Methods The present study is part of the CF-Epidemiological Network (CF-EpiNet project) and uses data from the UK Cystic Fibrosis Registry to describe the patterns of NIV use by

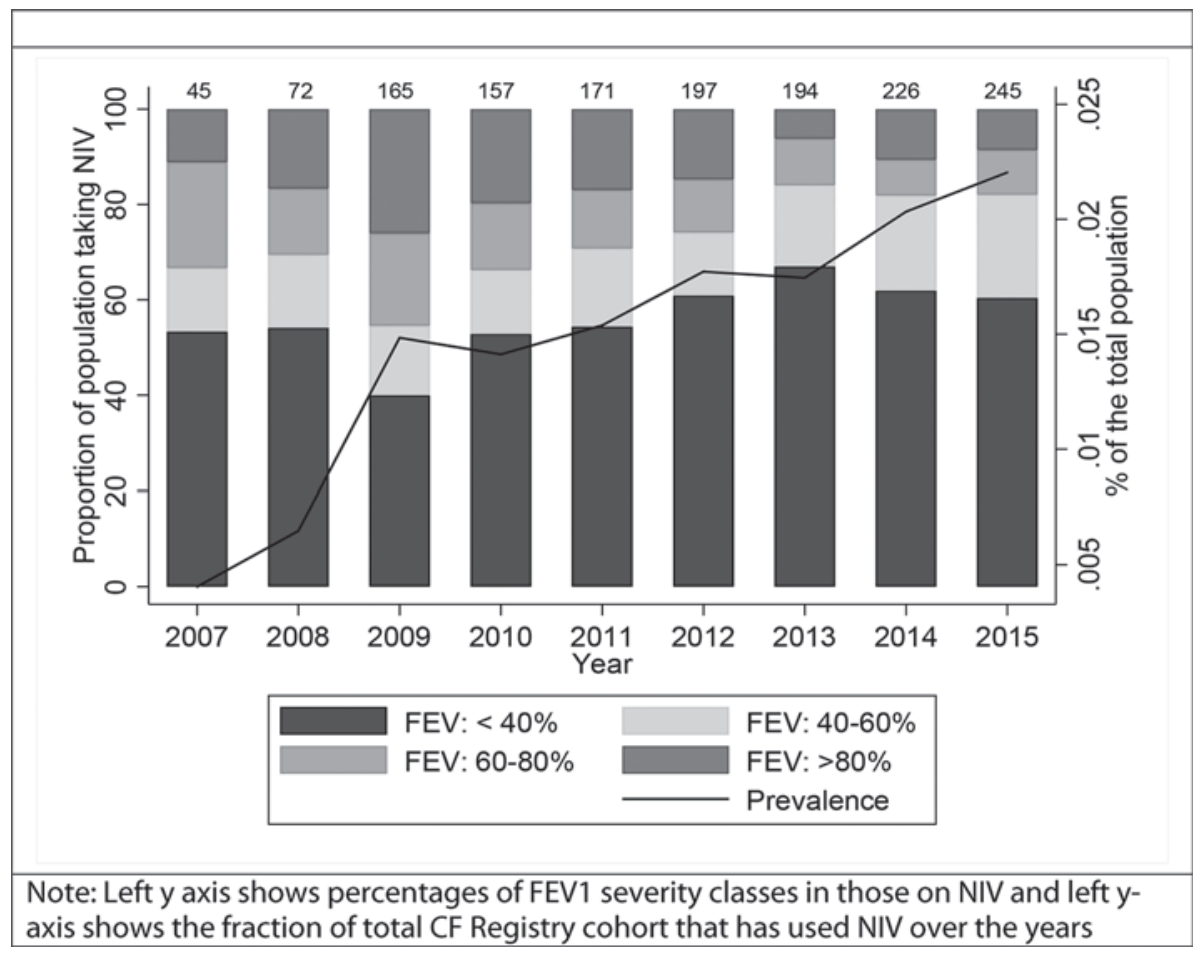

Abstract P250 Figure 1 Lung function distribution across years and prevalence of NIV use. 